\title{
What can we do against racism in mathematics education research?
}

\author{
David Wagner ${ }^{1} \cdot$ Arthur Bakker $^{2} \cdot$ Tamsin Meaney $^{3} \cdot$ Vilma Mesa $^{4}$ • \\ Susanne Prediger ${ }^{5}$. Wim Van Dooren ${ }^{6}$
}

Published online: 15 August 2020

(C) Springer Nature B.V. 2020

Recent events in the USA spotlight the racism that has permeated daily life since before the 1600s. In particular, some high-profile incidents of police killing unarmed Black citizens in 2020 , the public outcry, and the massive solidarity protests have provoked significant introspection. This spotlight on racism has stretched beyond the borders of the USA. Demonstrations in Australia, Canada, Colombia, England, Europe, and elsewhere are provoking public discussion about ingrained institutional and individual racism, particularly against people of African descent and Indigenous people. Despite this attention, there seems to be little change. We know of multiple incidents of police killing Black and Indigenous people in multiple countries in the month following the catalyst of George Floyd's murder in the USA. And we see new forms of old racism targeted at people of Asian descent (e.g., Das, 2020), blaming them for the COVID-19 pandemic.

The expression "Black Lives Matter," which became well-known in 2013 (https://blacklivesmatter.com/about/), has been used as a rallying cry in the recent protests in the USA and beyond. However, we worry that the news cycle is losing its focus on the Black Lives Matter protests and the associated introspection regarding racism. We recognize that many organizations have not lost interest and are taking action to address racism. We too, as editors of Educational Studies in Mathematics (ESM), commit ourselves to keep taking racism seriously.

Much of the scholarship in mathematics education regarding racism considers ways in which mathematics education as a white institutional space and mathematics teaching practices

David Wagner

dwagner@unb.ca

1 University of New Brunswick, Fredericton, Canada

2 Utrecht University, Utrecht, Netherlands

3 Western Norway University of Applied Sciences, Bergen, Norway

4 University of Michigan, Ann Arbor, MI, USA

5 TU Dortmund University, Dortmund, Germany

6 University of Leuven, Leuven, Belgium 
contribute to the oppression of Black, immigrant, and Indigenous children and youths (e.g., Battey \& Leyva, 2016; Khuzwayo, 2005; Martin, Gholson, \& Leonard, 2010; ValoyesChávez, 2014). There is also some scholarship that identifies global disparities within mathematics education research communities (e.g., Meaney, 2013; Mesa, 2004). We feel compelled to act, just like other journals (e.g., Nature: https:/www.nature.com/articles/d41586-02001723-9). We want to consider the role journals in general and ESM in particular might play in sustaining racism and perpetuating inequities within the field of mathematics education within and across countries. While it is difficult to find instances of overt racism in the peer review process, it is easy to see that systemic issues in the research field favor scholars and research from some regions more than others. We see that many of these issues are outside our control, such as finance and other resources, but we need to examine ourselves to identify our role in the inequities. For example, the dominance of English as lingua franca in worldwide academic dialog tends to oppress other traditions (Andrade-Molina, Montecino, \& Aguilar, 2020; Chellougui, Nguyen Thi Thu, \& Winsløw, 2016), but we can begin to change that in our corner of the wider academic community.

Mesa and Wagner (2019) reported on the countries of origin of contributors to ESM and raised questions about the significant disparities among the countries represented. When we consider these disparities and similar imbalances in other journals (Roberts, Bareket-Shavit, Dollins, Goldie, \& Mortenson, 2020) and conferences, we are compelled to ask whose lives are represented most and thus whose lives may appear to matter most in mathematics education research. We think of this question in two ways. First: To whose mathematics experiences does the research in ESM pay attention? In other words, whose mathematics learning and teaching are considered important enough to study? Whose mathematical practices are deemed interesting? Second: Which researchers matter? Whose questions are recognized as important enough for the world to read about in ESM? The disproportionate distribution of countries of origin of published papers might be taken as an indicator that readers and contributors to ESM do value some persons' mathematics education more than others'.

Clearly, this needs to change. Thus, in this editorial and the ongoing discussions among the editors, we examine our roles in this process and propose ways to begin to address the disparities. As noted in the article by Mesa and Wagner (2019), we editors have committed ourselves to extra work to support contributors whose first language is not English and to inviting reviewers and editorial board members from a diversity of countries, but we see that more action is necessary.

Here are some of our current thoughts. We identify our different voices here to signal the importance of perspective in such considerations, presented in the order in which they were written. The timing of vacations influenced who was able to contribute among our editor team.

\section{Susanne Prediger}

Racism has many different faces; in countries like Germany (where the category "race" was banned from discourses after the Nazi regime), it is disguised by distinctions between cultures or religions. In the international academic world, racism can be fueled by rankings of universities or countries. This is particularly subtle as there might be objective quality differences, but the global rankings can never do justice to an individual's achievements and can conceal the advantages of working in a privileged environment.

In these contexts, it is hard to balance between the inclusion of all researchers notwithstanding their contextual conditions and the need for a journal such as ESM to be selective due to the academic aim of high-quality standards. Are we always sensitive enough to how 
knowledge about typical inequities (between countries, cultures, universities, ...) can unconsciously turn into stereotypes and prejudices with an uncovered racist tendency?

In the long run, the aim must be to reduce inequities, not only stereotypes. How can we be inclusive and adhere to quality demands at the same time? Similarly to other contexts, in our editorial work, this tension means for us to keep asking ourselves:

- How can we avoid labeling and prejudices on the basis of country or university when we consider (a) authors, (b) reviewers, and (c) people to be cited?

- How can we contribute to more inclusion (a) by controlling our bias towards authors from underrepresented contexts in the journal and support the access to the international discourse for all authors, (b) by inviting reviewers from different contexts, including underrepresented countries, and (c) by making sure that authors from underrepresented countries are cited?

- How can we contribute to developing quality (a) by working hard with all authors (also from less privileged contexts) so that they can express their ideas in the best way possible, (b) by working hard on the editorial letters to compensate if poor reviews provide too limited support for authors, and (c) by including suggestions for references from underrepresented contexts?

- How can we continue becoming increasingly aware of the subtle mechanisms of labeling and stereotypes which we have internalized by socialization?

\section{Tamsin Meaney}

As Susanne writes, racism comes in many forms. Yet, it has an impact wider than the journals that mathematics education research gets published in. For example, mathematics education is a combination of both mathematics and education. Yet, in the articles that get published, "mathematics" is more often given precedence over "education." Why is it the case that "What is it about the mathematics which makes it difficult to learn" is prioritized over "What is it about the contexts that produces under-achievement in the learning of mathematics"? When under-achievement is mentioned, it is most often done so as a way of labeling a group (see, for example, Meaney, Edmonds-Wathen, McMurchy-Pilkington, \& Trinick, 2016). Generally, all the labeling does is to glue more strongly the under-achievement to these groups of students, so they or their families become responsible for the under-achievement. Petra Svensson described how teenagers in Sweden whose parents were immigrants had learnt from public discourse, particularly politicians' statements, that failure in tests such as PISA meant that the only way to improve their chances of doing well in mathematics was by having parents who were Swedish and by default who could help them with their homework (Svensson, Meaney, \& Norén, 2014). Ole Skovsmose (2005) has written many times about how the majority of children are ignored in mathematics education research, often under the guise of "what can be learnt (by Western countries) from this research?" On the other hand, it is presumed that children in these "other" countries can learn from what works in Western countries. What is published and what is not has implications well beyond the readership of mathematics education journals such as ESM. Our choices about what we support for publication can be racist if we consistently deny the experiences of some groups as being important and value only those from a small group.

Consequently, as reviewers and editors, there is a constant need to reflect on how we review an article and what assumptions it draws upon about quality research, which may result in 
exclusion rather than inclusion. We rarely see blatantly racist statements made either in journal articles or by reviewers, but this does not mean that racism is not there. It may be easier to see this by turning the issue around and saying who is privileged in reviews and editorial work? David Stinson (2017) writes about the need to consider white supremacy in mathematics education research as an alternative way of thinking about racism. This helps in the process of recognizing privilege. Do native English speakers have an advantage in writing journal articles? It is not easy to see this as an issue of racism, but it is certainly easy to see it as an issue of privilege. When we recommend alternative literature, what is the underlying assumption about the literature which was being used? Which researchers are we privileging by these comments as important mathematics education researchers? Are these researchers reflective of mathematics education researchers from across the world or do they represent a group with very similar demographics? If it is the latter, who are reviewers and editors saying can be important researchers in our field and by default who are we saying cannot be? As reviewers and as editors, we need to not just look for offensive statements of racism but also for these more subtle forms.

\section{David Wagner}

Questions about race prompt me to think of my conversations with people who identify with groups that are marginalized: their descriptions of their experiences and our conversations about possibilities for challenging structural inequities. I rely on these conversations because I sit in the intersection of most privileged demographics (white, male, cis-gendered, Canadian, etc.). The question of whose lives matter reminds me most vividly of an extended conversation with a friend when I was a teacher in eSwatini. As we warmed our hands over the heater in the teacher work room one day, he asked why Swazis are poor and Canadians rich. He wanted to talk about stereotypes and how they are used to explain disparities. In particular, he said that North American and European attributions of Africans being lazy and corrupt allowed us to feel comfortable with African poverty. For weeks, my Swazi friend and I talked about the (in)accuracy of these stereotypes and also of stereotypes that valorize North American and European ingenuity. We problematized the stereotypes by discussing people who embodied the values of their cultures: we found flaws in the apparent virtues and wisdom in the apparent flaws. When is ambition also dominance and repression? What level of wealth can someone have before being implicated in the violence of disparity? When is sustainable living and efficiency seen as laziness? Where is the line between corrupt corporate empires and corrupt government? I miss my friend.

In mathematics education research communities, I have noticed that conversations about the underrepresentation of scholarship from certain regions eventually invoke a tension between diversity and quality. We all say that we wish for more research from the underrepresented places, but we wonder how this can be done without sacrificing expectations for quality. This tension suggests assumptions of superiority much like the ones discussed with my friend. It identifies, for example, the theoretical and conceptual richness of European research, the rigor of North American research methods, and the beauty of the body of research developed with these strengths and the associated consensuses. I think that narrow conceptions of quality are dangerous. They are incestuous, blinding us to potential flaws and thus allowing the flaws to grow into proclaimed virtues.

There are different qualities of good research, different ways that research can give insight and challenge popular conceptions. I hope we can open discussion about different qualities of scholarship and how these qualities might represent and/or challenge conceptions in different contexts. In addition to talking about what can be good in research reporting, we need to talk 
about the problems with these apparent goods. I will point to one example of this kind of challenge to the status quo, but I mostly I want to leave the question open for discussion: Lihua $\mathrm{Xu}$ and David Clarke (2019) drew attention to significantly different cultural norms in Asian and English-speaking contexts to problematize assumptions and conceptualizations in research relating to what kind of communication is valued in mathematics classrooms.

I suggest that the first priority should be to discuss different qualities that research can bring to the field, and that people from well-represented countries (people like me) need to make space for people from underrepresented countries to lead these conversations. For an example, I point to a symposium convened by Aldo Parra, Arindam Bose, Jehad Alshwaikh, Monica González, Renato Marcone and Rossi D’Souza (2017) that theorized crisis from the perspectives of scholars from "developing" countries. Speaking in generalities (which is dangerous), I see researchers from underrepresented regions too often trying to fit the molds coming from Western Europe and the USA rather than building from their own perspectives on research qualities. Of course, it is hard to do quality work in someone else's framework, but colonialist storylines and demands of peer reviewers push researchers to try. I want to challenge this push and encourage research that builds on the wisdom of local worldviews, not the co-opting or forced adoption of the worldviews of others.

\section{Vilma Mesa}

So far, my colleagues have used the word racism and the expression white supremacy, and their usage - without definition - has prompted me to query, what do I mean by these terms? We have mentioned power, structures, and stereotypes.... Do we have a common understanding of these terms? This is my current understanding of racism: the belief that the inferiority of one group of people relative to another can be attributed to the color of their skin. Adscriptions of inferiority can be made for many other categories, as the ones suggested by Susanne. We know that genetically we are more alike across people from different skin colors than within people of the "same" color. Yet, we do continue to use the marker of skin color to make split decisions about worth, ability, and competence. White supremacy, to me, is the belief that the way in which white people do things is the way in which things must be done; that the ideal to which all humanity needs to aspire or organize itself must follow what white people have established. White supremacy needs racism and any other form of making other groups inferior: religion, language, age, wealth, health, body ability, etc. Ibram X. Kendi (2017) beautifully traces the origin of racist ideas to the need to sustain economic advantage and the ways in which European and American thinkers (male and white, by the way) justified white supremacy and slavery. He describes how laws were amended time and again to maintain the status quo; how the laws (and white male lawmakers, thinkers, philosophers, and yes researchers) managed to, not only uphold whiteness as an ideal for beauty, intelligence, goodness, wisdom, etc. but also convince everybody else that this was true. Power determines hierarchies among people; we construct these hierarchies with structures and symbols.

How are these hierarchies expressed in our academic process of publishing in journals? ESM has policies (e.g., length, style), procedures (one-way blind review, various experts read the same manuscript), and mechanisms to decide whether and when an article is ready for publication-based on a combination of the study reported in the manuscript, reviewers' comments, and editor's appraisal of both. But these have not been openly discussed nor historically scrutinized - and yet, we operate as if there is agreement and consensus about what they are. It is a struggle for me, to offer all the fair and equitable support that is needed to new researchers, especially to those from countries that are not well represented in the journal: I 
struggle to find reviewers who are willing to find merit in the work and put aside their own assumptions; I struggle with ways to present my suggestions so the researcher is not demoralized by the need of more revision; and I struggle with the demands on time that all of this requires. At the same time, I also wonder if I am participating in a colonialism project, another way of continuing imposing whiteness (relevancy, problems that matter, ways of writing, etc.) into the process of conducting and reporting research?

But beyond my personal interactions with individual researchers, I think we need to look critically at how current structures supporting the journal make it easier to maintain the status quo. Could our publisher ramp up their English language support? Could we have a larger editorial board to include wider country representation? Could we publish in more than one language? Could the publisher make it enticing for the editors-in-chief and the associate editors to hold frequent meetings to discuss the workings of the journal, as Dave suggested above? To what extent are the needs of the academics taking precedence over those of the publisher's shareholders? We need to critically assess how it is that the whole enterprise is being supported; otherwise, we will be seeking individual remedies to problems that are systemic. Perhaps then we can provide an authentic answer to the question of whose lives matter in mathematics education research.

\section{Wim Van Dooren}

As editors of one of the leading scientific journals in the field of mathematics education, we need to take issues of racism and any other inequities very seriously.

As indicated in the introduction, it is very clear that papers that get published in ESM are disproportionately distributed over countries of origin. As a consequence, certain mathematics experiences and practices remain in the blind spot of the research community. But a question that also needs to be addressed is whether this indicates that these mathematical practices are not deemed interesting, whether the questions raised by the non-published researchers are not considered important enough for the world to read about them. In other words, is the disproportionate distribution of published papers really an indicator that readers and contributors to ESM do value some persons' mathematics education more than others'?

In order to evaluate this, we first need to be aware that ESM and other journals (and to some extent also conferences) are the "endpoint" of the research process, where results of research are published. A long and very complex process (from the education and training of academic researchers and mathematics teachers, over organization of research and the way it is funded and how its output is valued, to the reporting and submission in journals like ESM) is involved. The range of manuscripts that we receive at ESM - and certainly the subset of manuscripts that finally get published - reflects only a very small part of that complex process. So, we need to look critically at how the disproportionate distribution of published papers would indeed reflect that readers and contributors to ESM do value some persons' mathematics education more than others'.

Looking at this complex process, from my experiences as an editor, I describe a few possible scenarios in which racism or other utterances of inequity could pop up, and lead to a disproportionate distribution in published papers. The elaboration of these scenarios is almost certainly incomplete, and I do not want to claim that all scenarios are equally real and/or relevant. Some may even simply reflect my narrow perspective as a 43-year old white, male, European professor in instructional psychology being active as an ESM associate editor (and probably having disproportionately many publications in journals). However, the scenarios do indicate that the disproportionate distribution of published papers does not necessarily reflect that some mathematics education practices and research practices are valued less. 
There are countries where a lot of mathematics education research happens, while in other countries, there may not even be research on mathematics education at all. This is an evident reason why some countries are underrepresented. But as an editor, I have seen that in some countries mathematics education research has started to grow only recently, while researchers are at the same time expected to show "scientific output" already after a very short time. This often seems to have led researchers from these countries to go for "quick gains": studies with limited novelty and no real contribution to the field, which again seriously hampers their chance of acceptance. In still other countries, a lot of novel research is done but there is no expectation at all that the research conducted is also published internationally. I take my own country (Belgium) as an example, but various aspects can also be recognized elsewhere. Most of our teachers (kindergarten, primary, and lower secondary) are not trained at university, but rather in institutions for higher education outside universities. Until recently, these institutions were not expected to conduct research, and while this is now changing, the kind of research they do is typically aimed at direct use in our own educational context. There is no expectation that the research is reported in international scientific journals. This may be a reason for a disproportionate underrepresentation, simply related to how research is organized.

Related to this is that I have seen that the research being done in many countries is mostly educational in a general sense, rather than specific to mathematics, even though the profile of the researchers is a mathematical one, and these researchers are often training mathematics teachers. There are many good reasons, including the fact that educational challenges in the countries where these researchers work are overarching the specific domains. Many of the submissions that I handle as editor are given a desk rejection for not fitting to the scope of the journal: While they in some way are about mathematics (for instance, the learning outcome is a mathematics test), they address a general educational theme that may be of interest to a wide readership, but they do not contribute specifically to a better understanding of the processes involved in teaching and learning mathematics. When a desk reject is given for such a reason, this is not a judgment of quality, but rather of the submission not being sent to the right journal. This would imply that countries underrepresented in ESM could be more strongly represented in other journals.

These scenarios describe reasons why certain countries may be disproportionately represented among the papers that are published — or even submitted - to ESM. And these reasons can hardly be related to issues of racism or other inequity in the way submissions are handled within ESM. But of course, many other scenarios do raise issues of racism or inequity that ESM can work at. The most blatant case would be if submissions get a lower chance of acceptance simply because the editor and/or reviewers would let prejudices about the authors interfere in judging the value of the conducted research and the quality of the report about this research. But more subtly, it can happen when the conducted research is good on its own, but the way it is reported shows flaws in the language, the scientific style, the range of literature included, and/or formalities like references and the description of statistics. These are important aspects in a paper, and they need to meet certain standards before a paper can get published. But some authors may not get a fair chance and sufficient help to revise their paper and get it to meet this standard, and mechanisms of racism could play a role in that. It becomes even more subtle if one realizes that in certain countries, other kinds of mathematics education research are being conducted, with a focus on other practices, topics, theoretical frameworks, et cetera. These different kinds of research might not always be adequately appreciated by the handling editors and/or by the reviewers, and issues of racism may be at play here, too. The question, however, is whether a journal like ESM can act on this on its own, or whether this is 
an issue of the broader mathematics education community that needs to take efforts to become more aware and more inclusive in light of such differences. As editors of ESM, we can play a role in this, of course, but a broader initiative seems needed for it to take effect. The ideas raised by the others in this editorial are important, in that respect, and I genuinely feel compelled to take action when needed to eradicate any inequity, be it due to racism or other reasons. But we should be very well aware that the disproportionate representation of countries among the published papers has many more reasons, and that ESM can only play its role within the broader mathematics education research community.

\section{Arthur Bakker}

What can I do against racism? To this big question, I only have humble, partial, temporary, and local answers that also depend on my positions as a human being, a white male, father, tourist, sports coach, consumer of coffee and chocolate, colleague, teacher, researcher, andmost relevant here - editor of ESM. As background to the topics and questions that in my view require courageous conversations (Singleton, 2014), I use two anecdotes.

The first dates back to 1999 when I traveled to the USA for the first time in my life. Just before landing, we were asked to fill in a form, which included a question on race. In many European countries, it is forbidden by law to register race — one of the reactions to World War II when it proved far too easy to identify Jews and other groups in society. I was shocked: Why would the US government need information about my race, and what would they do with such information? After a few minutes, I decided it was not the right moment to be anti-racist, but then I stumbled upon the next challenge: Which box to tick? "White" was not on the list. It was suggested to me that "Caucasian" came closest. Given that the Caucasus is just north of Turkey, with very diverse ethnic groups, I found this hard to believe. It seems typical of white people that they are rarely confronted with the issue of race (cf. the story about teacher Anne in Horn, 2017, pp. 26-27), but this was one such moment for me: Why would the USA government want to see me as Caucasian whereas the Dutch government puts me in their statistics as western immigrant, because my mother (a descendent of Maori and British ancestors) was born in New Zealand?

The second anecdote is also about a confrontation between American and European perspectives on race, but this time between researchers. In 2018, I participated in a 3-day workshop on engaging and diversifying STEM education, organized by Joe Polman and Melissa Braaten (funded by the United States National Science Foundation, NSF Grant No. 1757392, and the Netherlands Initiative for Education Research, NRO). All the researchers from a Dutch university would probably qualify as white, even though some of us prefer to stress the multiplicities of our identities (cf. Akkerman \& Meijer, 2011; Avraamidou, 2020); and none of us studied race or related themes. The US researchers were overtly more diverse, several with a background in critical race theory. Tension was rising in the group until a US scholar started a courageous conversation, asking whether racism was really not a big issue in the Netherlands or whether we were color blind.

This confrontation ignited a much appreciated dialog that had an enormous impact on me (and I have been told on many others). For us, colorblindness was a virtue ("I only see people, not their race"), but we started to realize that there is a high price that we pay for not wanting to talk about race and not being allowed to register racial information. Post-World War II, the fear of racialization in Europe (M'charek, Schramm, \& Skinner, 2014) seems to have led to a situation where we do not know much about racism in our 
educational system. For example, I found hardly any studies related to racism or ethnicity in Dutch mathematics education (what I found was mostly through a group of Flemish authors: Stevens, Clycq, Timmerman, \& Van Houtte, 2011). With the current protests in numerous countries and actions at universities, there seems to be more interest in finding ways to study racism but the European privacy law and guidelines of ethical review boards forbid collection of race information except under very special conditions. I stress this point because European reviewers may be surprised by reports on racial differences, whereas reviewers from the USA may wonder why their European colleagues did not collect that information. Note for instance that Roberts et al. (2020) advise authors to "detail the racial demographics of their samples" (p. 10)-a recommendation that makes sense in one context but is nearly impossible in another. Note also that my examples from the USA versus Europe show my ignorance about how these issues play out in other parts of the world (cf. Kapuściński, 2018).

After the workshop, I have had many conversations with colleagues and students about the uncomfortable but helpful confrontation between US and Dutch scholars. One recurring question was to what extent we could sensibly use the conceptual frameworks on race developed by researchers from the USA and South Africa. The general opinion, in my own words, seems to be that much conceptual and empirical work needs to be done to answer this question. The USA and South Africa have very specific histories in which the meanings of race, white supremacy (Bonilla-Silva, 2006; Hooks, 2003), and white innocence (Wekker, 2016) are rooted. I also have the impression that other countries may need somewhat different languages to reach their local audiences. For example, I have noted that many Dutch people prefer to talk about discrimination (ethnicity, gender, sexuality, etc.) rather than racism. Furthermore, the meanings of many of these terms, in particular what counts as politically correct, change rather fast (M'charek et al., 2014).

Although many mechanisms, in whichever formulation, may be rather universal (see examples mentioned by Vilma), cultural-historical studies tend to show how local manifestations can be very different. As Tamsin pointed out, stigmatizing and discrimination may manifest differently in different cultures, just like the experiences of Maori, Aboriginals, and other Indigenous people may differ from Turks in Germany or the Netherlands. De Haan, Keizer, and Elbers (2010) discovered even subtler differences: "power relations in classrooms between Dutch and immigrant students radically shift when students move from academic talk to more open, free talk" (p. 176). Their findings suggest that identity is much more contextually contingent than typical talk about black and white suggest (see also Nasir \& Hand, 2008).

Another recurring theme in our local discussions is that it is so hard to have transformative conversations such as we Dutch had with the US visitors. Along with other white colleagues, I have found it challenging to counter the anger expressed by antiracists (e.g., Weiner, 2014). I have felt guilt for being white and male as well as the colonial history of my country and its late abolishment of slavery (Balkenhol, 2014). In some discussions, arguments are swiped away as white innocence or white supremacy. The result is that we feel like elephants tiptoeing in a porcelain cabinet, as we say in Dutch. And what is worse: We feel labeled white with many privileges but without any nuance or justice to individual identities. However, when it comes to anger and guilt, my view has changed after reading Audre Lorde's work, in particular her paper Uses of Anger: Women Responding to Racism (Lorde, 2018). Characterizing herself as Black, lesbian, mother, warrior, and poet, she wrote: 
I cannot hide my anger to spare you guilt, nor hurt feelings, nor answering anger; for to do so insults and trivializes all our efforts. Guilt is not a response to anger; it is a response to one's own actions or lack of action. If it leads to change then it can be useful, since it is then no longer guilt but the beginning of knowledge. (p. 30)

What do the aforementioned reflections imply for a journal such as ESM?

First of all, we need critical discussion about implicit norms and explicit guidelines in the review and publishing process. As these have grown historically, the problem is that some of these may privilege those who are already privileged. For example, it is quite common for reviewers to ask authors to join the international debate, but what if this debate is dominated by a particular group? In other words, it is possible that our norms and guidelines are defined in ways that are blind to some of the many colors of quality.

The risk of monolithic views on research is criticized by Biesta (2020) in an inspirational book titled Educational Research: An Unorthodox Introduction. The risk of the orthodox (Greek for "the right opinion") is that guidelines become rigid and blind to context. His plea for unorthodox views on educational research appeals to me because if anything is clear from our discussions as editors, it is that current norms and procedures need to be scrutinized and rethought to ensure that inequitable shackles are broken. For example, it is an orthodox expectation in qualitative research to report interrater reliability with measures such as Cohen's kappa or Krippendorff's alpha. In some cases, such indicators may be useful, but there can be situations in which such reliability measures are not saying much about research quality (Thomas, 2017) or where alternative quality procedures may be more suitable (e.g., Akkerman et al., 2008).

Another orthodoxy that Biesta (2020) questions, with reference to Dewey, is that of the desire for objectivity as opposed to subjectivity. In his view, educational research needs to go beyond the dichotomy between the two. Under the banner of the ideal of objectivity, much harm can be done. When applied to the topic of avoiding racism in academia, I think we should avoid the orthodoxy of trying to make mathematics education research even more objective, with the risk of erasing the human from our work. Rather, we need a more human science.

Second, although I have never seen reviewer comments that I would label as racist, we have heard stories about unfair comments or expectations, sometimes in disguise of a less controversial norm (e.g., the aforementioned quality of English). And there seems to be asymmetry in what authors are expected to explain about their country's educational system. For example, it would be unfair if researchers from the USA would not have to explain anything about their situation, whereas Namibian researchers are asked to spell out the specificities of their educational context.

Third, does our (somewhat flexible) word limit privilege some types of research or researchers? What are the pros and cons of single and double blind and other review procedures (Baldwin, 2015; Mesa \& Wagner, 2019)? Can we require authors to engage conscientiously with the politics of citation (Mott \& Cockayne, 2017)?

I think that no formal procedures will alleviate the racism problem (Lorde, 2018), but talking about procedures will help create awareness of the potential biases of each. The history of psychology shows that a focus on fear of bias may lead to rigor (literally "stiffness"), but not necessarily much theoretical progress (Flis, 2018).

Instead I would like to invite reviewers to articulate their own ethical ideals on reviewing. In my view, inspired by Levinas (e.g., Levinas, 2003; Strhan, 2012), we as editors and reviewers need to make an attempt to meet the Other (which he mostly capitalizes), even if 
mediated through a manuscript about a scientific study. Someone's face, Levinas metaphorically argues, does an appeal to my ethical responsibility for this person. Even though as an editor or reviewer, I only see someone's manuscript and not literally their face, I would rather focus on openness and vulnerability than fear and rigor. Authors typically put their life and soul into their work, and devote scarce resources on their research. I know of no slower conversation than that between authors, editors, and reviewers, but it is a dialog. The key to me in realizing a fair, nonracist review process is recognizing that this dialog is not purely epistemological but primarily ethical. With such an ethical starting point, I am more optimistic that reviewers and editors continue to ask the big question: What can we do against racism?

Many wisdom traditions and literature on racism or oppression tell us to be reticent in trying to "fix" this. For example, in the Tao Te Ching, we find:

If a country is governed with tolerance,

the people are comfortable and honest,

If a country is governed with repression,

the people are depressed and crafty.

When the will to power is in charge,

the higher the ideals, the lower the results.

Try to make people happy,

and you lay the groundwork for misery.

Try to make people moral,

and you lay the groundwork for vice. (Mitchell, 1991, chapter 58)

It is further clear that most of our editors are white and despite various origins, we all live in firstworld countries with resources to do our editorial work (even though most of us do not get time or "course relief" from our universities). The racism literature warns that white people trying to help others may only reinforce white supremacy (Bonilla-Silva, 2006; Gillborn, 2008; Wekker, 2016). Lorde (2018) notes that The master's tools will never dismantle the master's house (title of one of her papers). Freire's (1970) work also shows how complex it is for the privileged to empower others. As a journal, we need to gain a better sense of institutional racism in the review process (assuming there is despite everyone's efforts) before implementing formal procedures. Hence our call for dialog and action below.

\section{Calls for dialog and action}

Our reflection on our roles in privileging some lives over others in mathematics education research compels us to action as editors. We commit ourselves to increasing our awareness and understanding of challenges experienced by contributors, and to keep working on fair reviewing processes. We also see the need for action in our other roles as reviewers, as conference leaders, as university teachers educating future researchers, and in our many less formal interactions within mathematics education research communities. We hope to provoke others to reflection and action, too.

We also invite mathematics educators to tell us stories of unfair treatment to improve our understanding. Further, we invite suggestions for more equitable practices and of potential editorial board members from underrepresented communities. Email any of us: Arthur Bakker at a.bakker4@uu.nl, David Wagner at dwagner@unb.ca, Susanne Prediger at prediger@math.tu-dortmund.de, Tamsin Meaney at tamsin.jillian.meaney@hvl.no, Vilma Mesa at vmesa@umich.edu, Wim Van Dooren at wim.vandooren@kuleuven.be, using the 
subject "nonracist reviewing." Another possibility is to submit a "letter to the editor" to ESM (see e.g., Proulx \& Maheux, 2019; Simpson, 2020).

Finally, we are pleased to announce an upcoming special issue of Educational Studies in Mathematics on "Race, racism, and racialization in mathematics education: global perspectives." This special issue will consider the concepts and practices much more deeply and broadly than we have in this editorial. It will be guest-edited by Danny Bernard Martin, Luz Valoyes-Chávez, and Paola Valero, who began organizing the special issue long before 2020. See the journal's website under "updates" and the back matter of Volume 104, Issue 3, for details and the call for papers.

Acknowledgments We would like to thank colleagues who provided helpful input: Lucy Avraamidou, Michiel and Sofie Doorman, Na’ilah Suad Nasir, Bill Penuel, Anne Peters, Joe Polman, Luz Valoyes-Chávez, and Bjorn Wansink.

\section{References}

Akkerman, S., Admiraal, W., Brekelmans, M., \& Oost, H. (2008). Auditing quality of research in social sciences. Quality \& Quantity, 42(2), 257-274.

Akkerman, S. F., \& Meijer, P. C. (2011). A dialogical approach to conceptualizing teacher identity. Teaching and Teacher Education, 27(2), 308-319.

Andrade-Molina, M., Montecino, A., \& Aguilar, M. S. (2020). Beyond quality metrics: Defying journal rankings as the philosopher's stone of mathematics education research. Educational Studies in Mathematics, 103(3), 359-374.

Avraamidou, L. (2020). "I am a young immigrant woman doing physics and on top of that I am Muslim": Identities, intersections, and negotiations. Journal of Research in Science Teaching, 57(3), 311-341.

Baldwin, M. (2015). Making "Nature”: The history of a scientific journal. University of Chicago Press.

Balkenhol, M. (2014). Tracing slavery. An ethnography of diaspora, affect, and cultural heritage in Amsterdam. (Doctoral dissertation, Vrije Universiteit Amsterdam)

Battey, D., \& Leyva, L. A. (2016). A framework for understanding whiteness in mathematics education. Journal of Urban Mathematics Education, 9(2), 49-80.

Biesta, G. (2020). Educational research: An unorthodox introduction. Bloomsbury.

Bonilla-Silva, E. (2006). Racism without racists: Color-blind racism and the persistence of racial inequality in the United States. Rowman \& Littlefield.

Chellougui, F., Nguyen Thi Thu, H., \& Winsløw, C. (2016). Language diversity in research on language diversity in mathematics education. In R. Barwell, P. Clarkson, A. Halai, M. Kazima, J. Moschkovich, N. Planas, M. Setati-Phakeng, P. Valero, \& M. Villavicencio (Eds.), Mathematics education and language diversity. The 21st ICMI Study (pp. 263-278). Springer.

Das, L. T. (2020). When the jokes aren't funny. Science, 369(6501), 342.

De Haan, M., Keizer, R., \& Elbers, E. (2010). Ethnicity and student identity in schools: An analysis of official and unofficial talk in multiethnic classrooms. European Journal of Psychology of Education, 25(2), 176-191.

Freire, P. (1970). Pedagogy of the oppressed. Herder and Herder.

Flis, I. (2018). Discipline through method: Recent history and philosophy of scientific psychology (1950-2018) (Doctoral dissertation, Utrecht University).

Gillborn, D. (2008). Racism and education: Coincidence or conspiracy? Routledge.

Hooks, B. (2003). Teaching community: A pedagogy of hope. Psychology Press.

Horn, I. S. (2017). Motivated: Designing math classrooms where students want to join in (pp. 26-27). Heinemann.

Kapuściński, R. (2018). The other. Verso Books.

Kendi, I. X. (2017). Stamped from the beginning: The definitive history of racist ideas in America. Random House.

Khuzwayo, H. B. (2005). A history of mathematics education research in South Africa: The apartheid years. In R. Vithal, J. Adler, \& C. Keitel (Eds.), Researching mathematics education in South Africa. Perspectives, practices, and possibilities (pp. 307-328). Cape Town, South Africa: HSRC Press.

Levinas, E. (2003). Humanism of the other. University of Illinois Press.

Lorde, A. (2018). The master's tools will never dismantle the master's house. Penguin. 
M'charek, A., Schramm, K., \& Skinner, D. (2014). Technologies of belonging: The absent presence of race in Europe. Science, Technology, \& Human Values, 39(4), 459-467.

Martin, D., Gholson, M., \& Leonard, J. (2010). Mathematics as gatekeeper: Power and privilege in the production of power. Journal of Urban Mathematics Education, 3(2), 12-24.

Meaney, T. (2013). The privileging of English in mathematics education research, just a necessary evil? Keynote presentation. In M. Berber, K. Brodie, V. Firth, \& K. Le Roux (Eds.), Proceedings of the 7th Mathematics, Education and Society Conference (vol. 1, pp. 65-84). Cape Town, South Africa: MES7.

Meaney, T., Edmonds-Wathen, C., McMurchy-Pilkington, C., \& Trinick, T. (2016). Distribution, recognition and representation: Mathematics education and Indigenous students. In K. Makar, S. Dole, J. Visnovska, M. Goos, A. Bennison, \& K. Fry (Eds.), Research in mathematics education in Australasia 2012-2015, (pp. 143-164). Singapore: Springer.

Mesa, V. (2004). JRME in the global village: Parlez vous français? Habla ud. Español? Journal for Research in Mathematics Education, 35(1), 2-4.

Mesa, V. \& Wagner, D. (2019). Behind the door: A critical look at the process of publication in Educational Studies in Mathematics. Educational Studies in Mathematics, 101(3), 301-324.

Mitchell, S. (1991). Tao te ching: A New English version. Harper Collins.

Mott, C., \& Cockayne, D. (2017). Citation matters: Mobilizing the politics of citation toward a practice of 'conscientious engagement'. Gender, Place \& Culture, 24(7), 954-973.

Nasir, N. I. S., \& Hand, V. (2008). From the court to the classroom: Opportunities for engagement, learning, and identity in basketball and classroom mathematics. The Journal of the Learning Sciences, 17(2), 143-179.

Parra, A., Bose, A., Alshwaikh, J., González, M., Marcone, R. \& D’Souza, R. (2017). "Crisis" and interface with mathematics education research and practice: An everyday issue. Proceedings of the $8^{\text {th }}$ Mathematics, Education and Society Conference (Vol. 1, pp. 174-178). Volos, Greece.

Proulx, J., \& Maheux, J. F. (2019). Effect sizes, epistemological issues, and identity of mathematics education research: A commentary on editorial 102(1). Educational Studies in Mathematics, 102(2), 299-302.

Roberts, S. O., Bareket-Shavit, C., Dollins, F. A., Goldie, P. D., \& Mortenson, E. (2020). Racial inequality in psychological research: Trends of the past and recommendations for the future. Perspectives on Psychological Science, 174569162092770. https://doi.org/10.1177/1745691620927709

Simpson, A. (2020). On the misinterpretation of effect size. Educational Studies in Mathematics, 103(1), 125133.

Singleton, G. E. (2014). Courageous conversations about race: A field guide for achieving equity in schools. Corwin Press.

Skovsmose, O. (2005). Travelling through education: Uncertainty, mathematics, responsibility. Rotterdam: Sense Publishers.

Stevens, P. A., Clycq, N., Timmerman, C., \& Van Houtte, M. (2011). Researching race/ethnicity and educational inequality in the Netherlands: A critical review of the research literature between 1980 and 2008. British Educational Research Journal, 37(1), 5-43.

Stinson, D.W. (2017). Researching race without researching White supremacy in mathematics education research: A strategic discursive practice. In A. Chronaki (Ed.), Proceedings of the 9th International Mathematics Education and Society Conference (MES9, Vol. 2, 901-912). Volos, Greece: MES9. Retrieved from http://mes9.ece.uth.gr/portal/images/proceedings/MES9_Proceedings_low_Volume2.pdf.

Strhan, A. (2012). Levinas, subjectivity, education: Towards an ethics of rädical responsibility. Wiley.

Svensson, P., Meaney, T., \& Norén, E. (2014). Immigrant students' perceptions of their possibilities to learn: The case of homework. For the Learning of Mathematics, 34(3), 32-37.

Thomas, G. (2017). How to do your research project: A guide for students. Sage.

Valoyes-Chávez, L. (2014). Colombian teachers' expectations of black and poor students' ability to learn algebra. (Doctoral dissertation, University of Missouri)

Weiner, M. F. (2014). The ideologically colonized metropole: Dutch racism and racist denial. Sociology Compass, 8(6), 731-744.

Wekker, G. (2016). White innocence: Paradoxes of colonialism and race. Duke University Press.

$\mathrm{Xu}, \mathrm{L} .$, \& Clarke, D. (2019). Speaking or not speaking as a cultural practice: Analysis of mathematics classroom discourse in Shanghai, Seoul, and Melbourne. Educational Studies in Mathematics, 102(1), 127-146.

Publisher's note Springer Nature remains neutral with regard to jurisdictional claims in published maps and institutional affiliations. 